\title{
THE IMPACT OF PERCEPTIONS OF LEADERSHIP STYLE, USE OF POWER, AND CONFLICT MANAGEMENT STYLE ON ORGANIZATIONAL OUTCOMES
}

\author{
VIRGINIA P. RICHMOND \\ JOHN P. WAGNER \\ JAMES C. MCCROSKEY
}

The degree of association between supervisor and subordinate perceptions of the supervisor's leadership style, use of power by the supervisor, and the supervisor's conflict-management style was studied in 87 organizational units representing five service-oriented organizations. The ability of the supervisors' and subordinates' perceptions, individually and jointly, and the discrepancy between these perceptions to predict subordinate satisfaction with supervision and work, subordinate solidarity with supervisor, and degree of subordinate anxiety about communicating with the supervisor were also examined.

Virginia P. Richmond (Ph.D., University of Nebraska, Lincoln, 1977) is Associate Professor of Speech Communication at West Virginia University. James C. McCroskey (D.Ed., Penn State University, 1966) is Chairperson at West Virginia University in the Speech Communication Department. John P. Wagner received his M.A. in Speech Communication from West Virginia University in August 1980.

Two of the major concerns of most organizations in contemporary society are productivity and employee satisfaction. In profit-making organizations, productivity is directly related to the achievement of the primary goal of the organizationincreasing the profit margin. In non-profit organizations increased productivity can lead to increased service. Employee satisfaction, although frequently not directly related to productivity, is tied to turnover rates and absenteeism which are major financial drains on profit and non-profit organizations alike.

Literally thousands of studies have been reported which have sought to link a wide variety of variables with productivity and/or satisfaction. A substantial number of these studies have examined the role of communication in increasing productivity and satisfaction. A general conclusion that may be drawn from this research is that communication between supervisor and subordinates does have an important impact. However, the way(s) that impact is achieved remains the concern of contemporary research.

The three concerns of the present investigation are leadership style, use of power, and management of conflict. All three are tied directly to the communication between supervisor and subordinates. All three have been found in previous research to be related to productivity and/or employee satisfaction (for leadership, see McGregor, 1960; Likert, 1961; Tannenbaum \& Schmidt, 1958; Fiedler, 1965; for power, see Pelz, 1952; Thibaut \& Riecken, 1955;
Student, 1968; for conflict, see Deutsch, 1973; Katz \& Kahn, 1966; Berelson \& Steiner, 1964).

\section{Theoretical Orientation}

A mediational model of the relationship between the behaviors of supervisors and the productivity and satisfaction of subordinates was employed in the current investigation. The components of that model include the supervisor's intent, the supervisor's behavior, the subordinates' perceptions of the supervisor's behavior, and the resulting satisfaction and productivity of the subordinate.

This perspective views subordinates' perceptions as the primary precursors of their productivity and satisfaction. One, but only one, of the elements impacting those perceptions is the behavior of the superior. Many other factors, most of which are not under the direct control of the supervisor, also impact subordinate perceptions. Working conditions, the work task, the personality of the subordinate, and family and community concerns are a few of the other important elements which impact subordinate perceptions.

Training of supervisors usually focuses on altering the way they see their organizational role (their intent) and modifying their behavior. Often, the model employed is highly instrumental-injecting certain new behaviors or removing certain old behaviors is assumed to modify subordinates' perceptions and result in increased productivity and/or 
Because of the conditions imposed upon this research by the managers of the organizations studied, we were unable to obtain data related to employee productivity. Consequently, the outcome variable studied were all in the general area of employee satisfaction. Specifically, these included subordinate satisfaction with supervision, subordinate satisfaction with work, subordinate perceptions of solidarity (closeness) with their supervisor, and subordinate perceptions of their anxiety about communicating with their supervisor.

The first three research questions bearing on outcome variables were directed toward testing the assumption underlying our theoretical model as outlined above. These questions were:

$Q_{4}$ To what extent are superior and subordinate perceptions colinear predictors of outcomes?

$Q_{5}$ To what extent are superior perceptions independent predictors of outcomes?

$Q_{6}$ To what extent are subordinate perceptions independent predictors of outcomes?

The final research question was directed towards discrepant supervisor/subordinate perceptions. The concern was with the potential impact on outcome variables of such discrepant perceptions. Since subordinate perceptions can be either higher or lower than those of superiors, both positive and negative perceptions are of concern. The final research question, therefore, was:

$Q_{7}$ To what extent are positive and negative discrepancies between superior and subordinate perceptions predictive of outcomes?

\section{Method}

\section{Sample}

The sample for this investigation included 96 units in five service-oriented, publicly-supported organizations. Participation in the research was completely voluntary and anonymity was assured. A total of 87 supervisors and 432 subordinates participated. Data obtained for supervisors or subordinates for which no counterpart data were available are not reflected in these figures and were not included in any data analyses.

To insure anonymity each supervisor was assigned a random code number. The supervisor informed her/his subordinates of that code number for use in their completion of the research instruments. Instruments were distributed to each unit personally. Because of requests by some unit supervisors, some units completed the instruments at special meetings with the researcher present. Subjects in most units completed the instruments on their own time and returned them to the researcher by mail. Reports of aggregate data were made to each of the five organizations as a condition of their cooperation in the research. None of the organizations had a financial involvement in the project.

\section{Measures}

In order to probe the research questions outlined above, measures of leadership style, use of power, conflict management style, satisfaction with supervision, satisfaction with work, solidarity with supervisor, and anxiety about communicating with supervisor were employed. Subordinates completed all of the measures, supervisors only the first three. Each measure is discussed below.

Leadership Style. Leadership style was operationalized and measured by the scale developed by Richmond and McCroskey (1979). This instrument places leadership style on a 19-point continuum ranging from Tell through Sell and Consult to Join, with five points separating each of the four classification points. This instrument is based on the earlier work of Tannenbaum and Schmidt (1958) and Sadler (1970) and has been found to have satisfactory reliability (test-retest $r=.85$ ) in previous research. In the present investigation, since the measure is a single scale and was administered only once, it was not possible to estimate the scales' reliability.

Use of Power. The five bases of power conceptualized by French and Raven (1959) were investigated in this study. The measures employed were those advanced by Richmond, McCroskey, Davis, and Koontz (1980). This measure is based on the earlier work of Student (1968) which found the bases of power to be related to both productivity and satisfaction. Student (1968) employed only a single scale for each power base. Richmond, et. al., expanded the measure to five items for each power base in order to enhance reliability. In that research the reliability estimate for each power base exceeded .90 . Similar high reliability estimates were obtained in the present investigation (see Table 1).

Conflict Management Style. A survey of the literaturs uncovered no measure of conflict management style deemed appropriate for this investigation. Consequently, it was necessary to create such an instrument. Based upon earlier work of Sillars (1979) a 20-item instrument representing 20 conflict management strategies was generated. The instrument was administered in a 5-point, Likert-type response format.

Factor analysis of the data from the subordinates in this study indicated that the scale was not unidimensional. Oblique rotation analysis indicated two correlated factors. The first factor, labeled "activity," included 11 items and the second factor, labeled "dominance," included four items. Five items loaded on neither factor and no other factor included more than one item. Thus only the data for the items on the two factors were included in subsequent analyses. Although the sample of supervisors was not of sufficient size $(n=87)$ for factor analytic purposes, a factor analysis was conducted on these data and the two rotated factors were essentially the same as those obtained for the subordinate sample. The estimated reliabilities for both of the 
dimension scores were satisfactory for a new scale ( see Table 1), but additional items probably should be added to the dominance measure in future use to increase the reliability of that measure.

Satisfaction with Supervision and Work. The Job Descriptive Index (JDI), developed by Smith, Kendall, and Hulin (1969) was employed to measure subordinate satisfaction. Only the supervision and work dimensions were employed, since these have been found in previous research to be sensitive to the types of perceptions studied in this investigation while the other dimensions of the JDI have been found to be essentially unrelated to these perceptions. Previous research has indicated both the reliability and validity of these measures of satisfaction. The estimated reliability in the present investigation was quite satisfactory for both dimensions ( see Table 1).

Solidarity. Solidarity has been conceptualized by Brown (1965) and Wheeless (1976) as the degree of psychological closeness between two people. Increases in solidarity are seen as improving the climate for communication between people. The instrument used to measure solidarity in this investigation was developed by Wheeless (1978). The solidarity scale is a 20 -item, Likert-type instrument. Previous research has indicated the instrument has high reliability. The estimate in the present investigation also was quite satisfactory (see Table 1).

Communication Anxiety. Communication between supervisor and subordinate generally is viewed as an element more likely to lead to positive than negative consequenses for the organization. Anxiety about such communication would be expected to reduce the amount of communication sought by the subordinate as well as the effectiveness of that in which actually engaged (McCroskey, 1977). Reduced anxiety, therefore, is seen as a positive influence toward superior-subordinate communication.

Anxiety about communicating with one's supervisor was operationalized and measured by the Spielberger (1966) State Anxiety Inventory as modified for use with communication anxiety by Richmond (1978). This 20-item instrument was administered in 5-point, Likert-type format. Previous research has indicated high reliability and validity estimates for this measure. In the present investigation, the reliability estimate also was very satisfactory (see Table 1).

\section{Data Analyses}

The paired data for each of the supervisors and mean data for that supervisor's subordinates served as the unit of analysis for this study. Thus, the " $N$ " for each analysis was 87 . While this sample size is sufficient for correlational analyses (power above .80 for medium and large effect sizes with alpha $=.05$ ) according to the Cohen (1977) convention, it is insufficient to detect very small relationships. With regard to differences examined by analyses of variance, this sample size is sufficient only for detection of large effect sizes. Non-significant differences and relationships must be interpreted with these limitations in mind.

Our first three research questions were directed toward the magnitude of relationships between the perceptions of supervisors and subordinates. The

\section{Table 1}

Internal Reliability of Measures and Correlations of Supervisor and Subordinate Scores

\begin{tabular}{lccc}
\hline \multicolumn{1}{c}{ Measure } & $\begin{array}{c}\text { Supervisor } \\
\text { Reliability }\end{array}$ & $\begin{array}{c}\text { Subordinate } \\
\text { Reliability }\end{array}$ & $\begin{array}{c}\text { Correlation between } \\
\text { Supervisor \& Subordinate }\end{array}$ \\
\hline Leadership Style & $* *$ & $* *$ & $.23^{* * *}$ \\
Use of Power & & & .12 \\
Coercive & .95 & .98 & .15 \\
Legitimate & .94 & .98 & .05 \\
Reward & .96 & .99 & $-.26^{* * *}$ \\
Referent & .94 & .99 & -.15 \\
Expert & .97 & .98 & .04 \\
Conflict Management Style & & & $.45^{* * *}$ \\
Activity & .86 & .94 & \\
Dominance & .81 & .86 & $*$ \\
Outcome Variables & & & $*$ \\
Satisfaction with & & & $*$ \\
$\quad$ Supervision & $*$ & .94 & $*$ \\
Satisfaction with Work & $*$ & .91 & $* 94$ \\
Solidarity & $*$ & .96 & $*$ \\
Communication Anxiety & $*$ & & \\
\hline
\end{tabular}

* No data obtained from supervisors.

**No estimate possible.

*** Significant, $p<.05$. 
relationships were examined by Pearson correlations. Research questions 4-6 were concerned with the joint and independent predictive power related to the outcome variables of the supervisor and subordinate perceptions. These relationships were examined by multiple regression analyses with decomposition of obtained $\mathrm{R}^{2}$ to determine independent and colinear effects.

The final research question concerned the impact of perceptual discrepancies between supervisors and subordinates on the outcome variables. These potential impacts were probed with simple analyses of covariance with five levels. The covariates were the perceptual reports of the subordinates. The five levels were created on the basis of the degree to which perceptual reports of supervisors and subordinates differed. Based on the standard deviations of the subordinates' scores, the following categories were created: Much Lower, Lower, Same, Higher, Much Higher. When supervisor and subordinate scores were within one-half standard deviation of each other, they were placed in the "Same" category. When the scores were between one-half and one standard deviation apart, they were placed in the "Lower" and "Higher" categories - Lower if the subordinates' perceptions were lower than the supervisors, Higher if the reverse. When the scores were more than one standard deviation apart, they were placed in the "Much Lower" and "Much Higher" categories. All tests were conducted at the .05 level.

\section{Results}

The obtained correlations between supervisors' and subordinates' perceptions are reported in Table 1. The obtained correlation of .23 indicates some (about 5 percent) shared variance between supervisors and subordinates with regard to their perceptions of the supervisor's leadership style. Considerable shared variance (over 20 percent) was also observed on the dominance dimension of conflict management style. No significant correlations were obtained on the activity dimension of conflict management style and four of the five dimensions of power use. The other dimension of power use, referent power, generated a significant negative relationship. The more the supervisor felt he/she employed this type of power, the less use the subordinates perceived.

Table 2 reports the simple and multiple correlations of supervisor and subordinate perceptions with the four outcome variables. Table 3 reports the variance in the outcome measures predictable by supervisor and subordinate perceptions singly and jointly as determined by decomposition analyses for significant predictive models.

The results reported in Tables 2 and 3 indicate that the only shared perceptions which appear to account for meaningful variance in outcomes are those associated with the dominance dimension of conflict management style. Shared perceptions on this dimension were particularly predictive of satisfaction with supervision and with solidarity. Supervisors' perceptions of leadership style were significantly correlated with three outcome variables, supervisors' perceptions of use of coercive power were significantly associated with one outcome variable, and supervisors' perceptions of the dominance dimension of conflict management style were significantly correlated with three of the outcome measures. Decomposition analyses indicated, however, that supervisor perceptions accounted for meaningful unique variance in only one instance. Supervisor perceptions of leadership style were predictive of over 10 percent of the variance in subordinate satisfaction with work.

In contrast to the associations with supervisors perceptions, correlations between subordinates' perceptions and the various outcome measures indicated many meaningful relationships. Subordinate perceptions of leadership style, use of coercive and referent power, and both of the dimensions of conflict management style were the most predictive. Perceptions of use of legitimate, reward, and expert power, with the exception of one instance, were totally non-predictive.

Since our theoretical model suggests that subordinate perceptions function as mediators of outcome variables, these results can be viewed as supportive. An alternative explanation, however, might be advanced. Since the subordinate perceptions and outcome variables were generated by measures taken at the same time from the same people, it might be argued that obtained correlations could be an artifact stemming from multiple measurement. The fact that no significant correlations were obtained between several of the measures of power use and the outcome measures, however, substantially weakens this explanation.

Table 4 reports the covariance adjusted means for the discrepancy level classification for all analyses which generated significant overall models. Significant models were obtained for all four outcome measures for leadership style, referent pow$e r$, and the activity dimension of conflict management style. Significant models were obtained for three of the four outcome measures for coercive power and the dominance dimension of conflict management style. No significant models were obtained for reward, legitimate, or expert power.

An examination of Table 4 indicates that for most modeis only the covariate, representing the subordinates' perceptions on the relevant variable, accounted for significant variance in the outcome variables. The exceptions were in the analyses concerned with referent power and leadership style. Discrepancies between superior and subordinate perceptions of referent power accounted for significant variance on satisfaction with work and communication anxiety. When subordinates perceived their supervisor to have much higher referent power than did the supervisor, the subordinates were less satisfied with their work. However, when the super- 
Table 2

Simple and Multiple Correlations Between Supervisor and Subordinate Perceptions and Outcome Variables

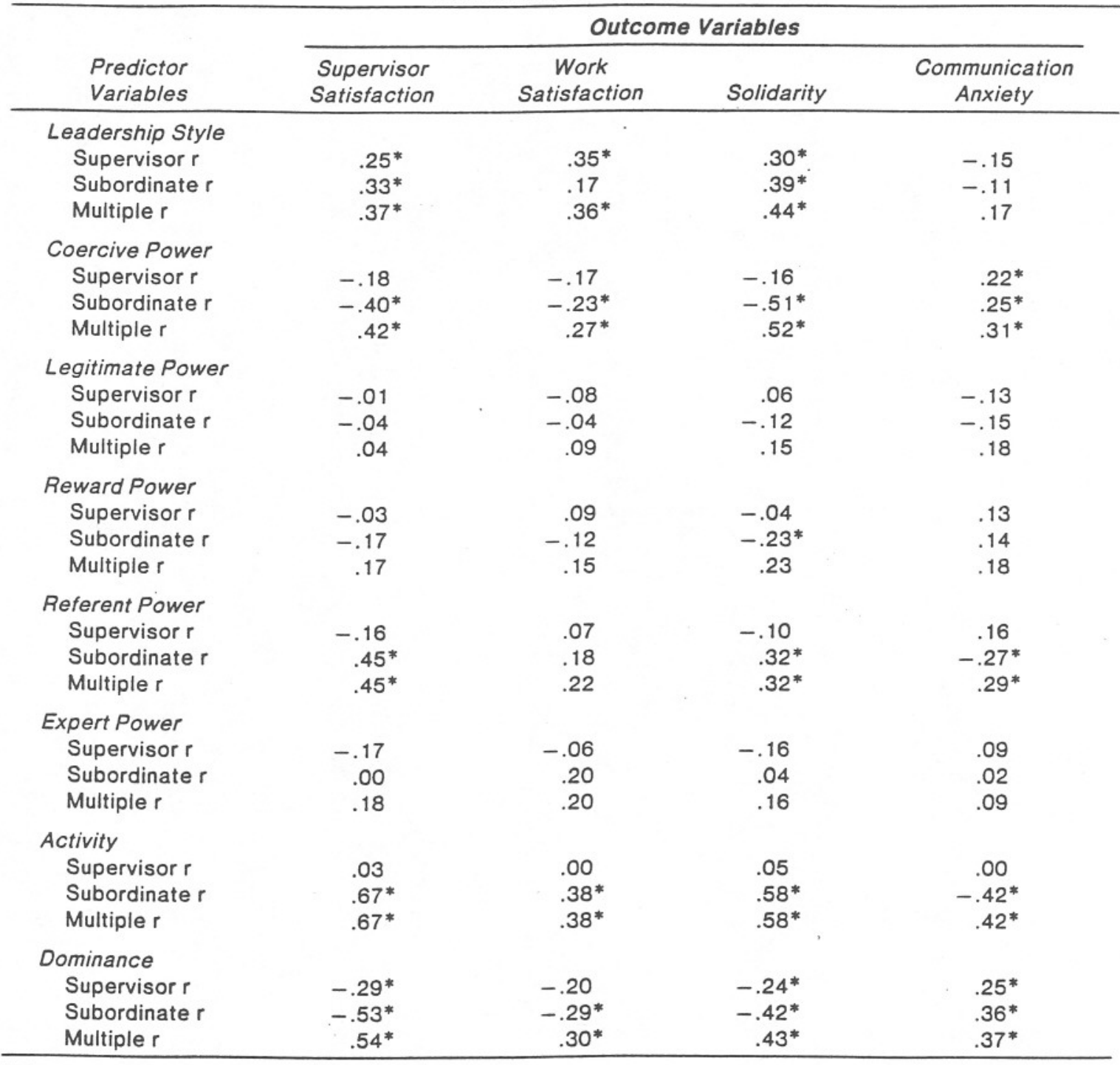

* Significant, $p<.05$.

visor was seen as having lower or much lower referent power than the amount viewed by the supervisor, the subordinates were more anxious about communicating with the supervisor.

The most striking results were those relating to discrepancies in perceived leadership style. While the correlation results reported above indicate that more positive outcomes are associated with a more employee-centered (consult to join) leadership style, the results of the discrepancy analyses suggest a major limitation to this apparent pattern. The lowest satisfaction and solidarity and highest anxiety was associated with much higher perceived leadership style scores of the subordinates compared to the supervisors. In contrast, the most satisfaction and solidarity and least anxiety were present when the subordinates reported moderately higher leadership style scores than the supervisors. In no instance was the "same" condition associated with the most positive outcome level.

\section{Discussion}

The following limitations of the sample in this study should be noted. First, all units studied represented publicly-supported, service-oriented organizations. Whether the results obtained can be generalized to profit-making or product-oriented organizations awaits future research. Second, this is an availability sample. Several organizations con- 
Table 3

Decomposition of Predictable Outcome Variance for Multiple Regressions with Significant Models

\begin{tabular}{|c|c|c|c|c|}
\hline $\begin{array}{c}\text { Predictor } \\
\text { Variables/Outcome }\end{array}$ & $\begin{array}{c}\text { Total } \\
\text { Model }\end{array}$ & $\begin{array}{l}\text { Unique to } \\
\text { Supervisor }\end{array}$ & $\begin{array}{c}\text { Unique to } \\
\text { Subordinate }\end{array}$ & $\begin{array}{c}\text { Colinear } \\
\text { Prediction }\end{array}$ \\
\hline $\begin{array}{l}\text { Leadership Style } \\
\text { Supervision } \\
\text { Work } \\
\text { Solidarity }\end{array}$ & $\begin{array}{l}.1380 \\
.1318 \\
.1978\end{array}$ & $\begin{array}{l}.0306^{*} \\
.1044^{*} \\
.0461^{*}\end{array}$ & $\begin{array}{l}.0776 \\
.0075^{*} \\
.1087\end{array}$ & $\begin{array}{l}.0298^{*} \\
.0199^{*} \\
.0431^{*}\end{array}$ \\
\hline $\begin{array}{l}\text { Coercive Power } \\
\text { Supervision } \\
\text { Work } \\
\text { Solidarity } \\
\text { Anxiety }\end{array}$ & $\begin{array}{l}.1758 \\
.0713 \\
.2658 \\
.0952\end{array}$ & $\begin{array}{l}.0163^{*} \\
.0177^{*} \\
.0083^{*} \\
.0328^{*}\end{array}$ & $\begin{array}{l}.1459 \\
.0460^{*} \\
.2435 \\
.0517\end{array}$ & $\begin{array}{l}.0136^{*} \\
.0076^{*} \\
.0140^{*} \\
.0108^{*}\end{array}$ \\
\hline $\begin{array}{l}\text { Referent Power } \\
\text { Supervision } \\
\text { Solidarity } \\
\text { Anxiety }\end{array}$ & $\begin{array}{l}.2034 \\
.1009 \\
.0834\end{array}$ & $\begin{array}{l}.0018^{*} \\
.0004^{*} \\
.0080^{*}\end{array}$ & $\begin{array}{l}.1786 \\
.0905 \\
.0585\end{array}$ & $\begin{array}{l}.0231^{*} \\
.0100^{*} \\
.0169^{*}\end{array}$ \\
\hline $\begin{array}{l}\text { Activity } \\
\text { Supervision } \\
\text { Work } \\
\text { Solidarity } \\
\text { Anxiety }\end{array}$ & $\begin{array}{l}.4552 \\
.1441 \\
.3417 \\
.1776\end{array}$ & $\begin{array}{l}.0000^{*} \\
.0000^{*} \\
.0009^{*} \\
.0001^{*}\end{array}$ & $\begin{array}{l}.4541 \\
.1441 \\
.3390 \\
.1776\end{array}$ & $\begin{array}{l}.0011^{*} \\
.0000^{*} \\
.0019^{*} \\
.0001^{*}\end{array}$ \\
\hline $\begin{array}{l}\text { Dominance } \\
\text { Supervision } \\
\text { Work } \\
\text { Solidarity } \\
\text { Anxiety }\end{array}$ & $\begin{array}{l}.2891 \\
.0883 \\
.1807 \\
.1034\end{array}$ & $\begin{array}{l}.0033^{*} \\
.0061^{*} \\
.0000^{*} \\
.0177^{*}\end{array}$ & $\begin{array}{l}.2034 \\
.0480^{*} \\
.1215 \\
.0431^{*}\end{array}$ & $\begin{array}{l}.0824 \\
.0342^{*} \\
.0592 \\
.0426\end{array}$ \\
\hline
\end{tabular}

*Shared variance of less than .05 should not be considered meaningful with this sample size.

tacted refused to participate. Third, since participation of supervisors and subordinates was completely voluntary, and many chose not to participate. the representativeness of the obtained data is unknown. All of these limitations should be considered when attempting to generalize the results of this investigation to other populations of supervisors and subordinates.

Our first three research questions concerned the degree to which supervisors and subordinates share perceptions of the supervisor's leadership style, use of power, and conflict management style. Our results indicate that generally there is little shared variance in these perceptions. While perceptions of leadership style were modestly related $(r=.23)$ and perceptions of the dominance dimension of conflict management style were moderately related $(r=.45)$, there was no relationship between perceptions of the activity dimension of conflict management style or the use of coercive, reward, legitimate, or expert power. The relationship between perceptions of use of referent power was significantly negative $(r=-.26)$.

The fact that positive association between supervisor and subordinate perceptions was observed only on the leadership style and dominance measures limited our ability to provide a meaningful answer to our fourth research question. This ques. tion was concerned with the extent to which shared perceptions are predictive of satisfaction, solidarity, and anxiety. Subordinate perceptions, as anticipated from our theoretical model, dominated the predictable variance in these outcome measures. However, the shared perceptions (colinearity) of dominance were a significant predictor of satisfaction with supervision and solidarity, and a modest predictor of anxiety and satisfaction with work. Similarly, shared perceptions of leadership style were a modest predictor of solidarity and satisfaction with supervision. The answer to our question, therefore, appears to be that when shared perceptions actually exist, they are likely to be associated with the types of outcomes examined in this study. The importance of this conclusion, however, must be tempered with the caveat that such shared perceptions may be the exception rather than the rule in on-going organizations.

Research questions 5 and 6 were directed toward the unique associations of supervisor's and subordinates' perceptions with organizational outcomes. The results provide relatively unambiguous answers to these questions. With regard to the association of supervisor perceptions with outcome variables, in only four of the 32 associations tested was the shared variance more than three percent and in only one instance was it more than five 
Table 4

Covariance Adjusted Means for Discrepancy Level Classifications for Significant Predictor/Outcome Models

\begin{tabular}{|c|c|c|c|c|c|c|c|c|}
\hline $\begin{array}{c}\text { Predictor/ } \\
\text { Outcome }\end{array}$ & $\begin{array}{l}\text { Subor- } \\
\text { dinate } \\
\text { Much } \\
\text { Lower }\end{array}$ & $\begin{array}{l}\text { Subor- } \\
\text { dinate } \\
\text { Lower }\end{array}$ & Same & $\begin{array}{l}\text { Subor- } \\
\text { dinate } \\
\text { Higher }\end{array}$ & $\begin{array}{l}\text { Subor- } \\
\text { dinate } \\
\text { Much } \\
\text { Higher }\end{array}$ & $\begin{array}{c}R^{2} \text { for } \\
\text { Covariate }\end{array}$ & $\begin{array}{c}R^{2} \text { for } \\
\text { Predictor ** }\end{array}$ & $\begin{array}{c}\text { Total } \\
R^{2} \\
\end{array}$ \\
\hline \multicolumn{9}{|l|}{ Leadership Style } \\
\hline Supervision & $85.5_{a}$ & $88.1_{b}$ & $84.2_{c}$ & $93.8_{\text {cd }}$ & $72.1_{\mathrm{abcd}}$ & $.10^{*}$ & $.20^{*}$ & $.30^{*}$ \\
\hline Work & $55.2_{\mathrm{a}}$ & $52.6_{b}$ & $51.1 \mathrm{a}$ & $55.7_{c}$ & $41.7_{\mathrm{abc}}$ & .03 & $.25^{*}$ & $.28^{*}$ \\
\hline Solidarity & $98.5_{a}$ & $93.1_{0}$ & $90.6_{\mathrm{ac}}$ & $103.9_{b c}$ & $75.4_{\mathrm{ab}}$ & $.15^{*}$ & $.23^{*}$ & $.38^{*}$ \\
\hline Anxiety & $54.2_{\mathrm{a}}$ & $51.2_{b}$ & $57.5_{c}$ & $50.7_{d}$ & $69.2_{\mathrm{abcd}}$ & .01 & $.13^{*}$ & $.15^{*}$ \\
\hline \multicolumn{9}{|l|}{ Coercive Power } \\
\hline Supervision & 83.0 & $88.3_{a}$ & $80.8_{\mathrm{ab}}$ & 82.1 & $87.9_{b}$ & $.16^{*}$ & .06 & $.22^{*}$ \\
\hline Work & $49.2 \mathrm{a}$ & $55.7_{\mathrm{ab}}$ & $49.3_{b}$ & 52.1 & 53.3 & $.05^{*}$ & .10 & $.15^{*}$ \\
\hline Solidarity & 89.0 & 97.0 & 93.0 & 92.0 & 93.5 & $.26^{*}$ & .02 & $.28^{*}$ \\
\hline \multicolumn{9}{|l|}{ Referent Power } \\
\hline Supervision & $81.9_{\mathrm{ab}}$ & 84.9 & $89.2_{\mathrm{a}}$ & $89.5_{b}$ & 84.4 & $.20^{*}$ & .05 & $.25^{*}$ \\
\hline Work & 50.7 & $55.8_{a}$ & $54.2_{b}$ & $55.6_{c}$ & $49.7_{\mathrm{abc}}$ & .03 & $.11^{*}$ & $.15^{*}$ \\
\hline Solidarity & 90.3 & 92.0 & 97.7 & 99.6 & 91.8 & $.10^{*}$ & .05 & $.15^{*}$ \\
\hline Anxiety & $60.3_{\mathrm{ab}}$ & $63.5_{\text {cde }}$ & $50.0_{\mathrm{ac}}$ & $47.8_{\text {bd }}$ & 54.4 & $.08^{*}$ & $.11^{*}$ & $.19^{*}$ \\
\hline \multicolumn{9}{|l|}{ Activity } \\
\hline Supervision & 84.2 & 85.4 & 86.3 & 82.4 & 84.9 & $.45^{*}$ & .01 & $.46^{*}$ \\
\hline Work & 52.3 & 51.4 & 52.2 & 48.7 & 53.4 & $.14^{*}$ & .02 & $.17^{*}$ \\
\hline Solidarity & 93.9 & 93.0 & 92.4 & 87.4 & 96.9 & $.34^{*}$ & .02 & $.36^{*}$ \\
\hline Anxiety & 55.3 & 58.5 & 57.1 & 53.2 & 53.2 & $.18^{*}$ & .01 & $.19^{*}$ \\
\hline \multicolumn{9}{|l|}{ Dominance } \\
\hline Supervision & 86.3 & 82.9 & 85.2 & 85.1 & 84.7 & $.29^{*}$ & .01 & $.29^{*}$ \\
\hline Solidarity & 94.3 & 89.3 & 94.0 & 91.5 & 95.0 & $.18^{*}$ & .02 & $.19^{*}$ \\
\hline Anxiety & 55.8 & 58.2 & 55.2 & $60.8_{\mathrm{a}}$ & $49.9_{\mathrm{s}}$ & $.13^{*}$ & .04 & $.17^{*}$ \\
\hline
\end{tabular}

* Significant, $p<.05$

**Covariate in each analysis is the subordinates' perception on the independent variable studied. The predictor variable represents the discrepancy classification based on the difference between supervisors' and subordinates' perceptions.

a-e Means for same Outcome Variable with same subscript are significantly different, $p<.05$ (two-tailed test).

percent. Thus, as posited by our theoretical model, a supervisor's intent (represented in this study as the supervisor's perceptions) is only associated with organizational outcomes to the extent that intent is reflected in modifications of the perceptions of subordinates.

The association between subordinates' perceptions and outcome variables, the concern of our sixth research question, was found to be significant in 18 of the 32 tests in this study (see Table 2). These significant relationships indicating shared variance ranging from five to 45 percent. Higher scores on activity, referent power, and leadership style were associated with more satisfaction and solidarity and less communication anxiety. Lower scores on coercive power and dominance were associated with more satisfaction and solidarity and less communication anxiety. Perceptions of legitimate and expert power were not associated with any of the outcome variables. Use of reward power was negatively associated with solidarity.

Taken as whole, the results discussed to this point indicate that the supervisor who wishes to generate positive impact on satisfaction with supervision, satisfaction with work, and solidarity and to reduce communication anxiety should strive to get her/his subordinates to perceive her/him as using a more employee-centered (consult-join) leadership style, avoiding use of coercive or reward power or exercising a dominant conflict management style, and using referent power and an active conflict management style. Perceptions of use of legitimate or expert power appear to have no relationship to the outcomes studied here, so the supervisor may not need to be concerned with modifying subordinate perceptions in this area.

The results relating to our last research question, however, suggest at least one modification in these 
general conclusions. This question addressed the issue of the impact of discrepant perceptions between supervisor and subordinate on organizational outcomes. The results indicated that if the subordinates perceived the supervisor as using a somewhat more employee-centered leadership style (consult to join) than he/she did, the subordinates were more likely to report higher satisfaction and solidarity and lower communication anxiety. However, if the discrepancy in the same direction became large, the impact on the outcome variables was the exact opposite.

We believe there is a relatively straight-forward explanation of this finding. Leadership styles which approach the employee-centered (join) end of the continuum greatly increase the degree to which subordinates are asked to participate in making decisions and/or make the decision themselves. When this approach becomes excessive, the supervisor may be seen as abdicating her/his responsibilities - the laissez faire leader - or even deserting the subordinate. The subordinate may feel that they are given more responsibility than their positions should require and, thus, are overworked or underpaid for the work expected. Such reactions could be expected to be reflected in negative outcomes of the type observed in this study. We conclude, therefore, that while the supervisor should attempt to be perceived as employing an employee-centered leadership style (consult-join), he/she must maintain a supervisory role and avoid being perceived as abdicating responsibility.

\section{Implications for Training Programs}

Several implications for training programs may be drawn from the results of this study, programs for both supervisors and subordinates. These may be grouped according to our main concerns in this research: leadership style, use of power, and conflict management style.

\section{Leadership Style}

Supervisory training programs have long included instruction in the area of leadership style, whether from the vantage point taken in this study or one of numerous other approaches. For the most part, such programs are directed toward how the supervisor should behave. Usually, the advice is to move toward an employee-centered or democratic style when possible. Such training, while probably useful, certainly is no guarantee that more positive organizational outcomes will be forthcoming. Our results indicate that there is relatively little shared perception of leadership style between supervisors and subordinates. Since subordinate perceptions are most associated with desired outcomes, unless these perceptions are modified by the supervisor, changes implemented as a function of training are likely to have little positive impact.

The implications we draw from this analysis is that training to modify leadership style is a necessary but not sufficient condition for organizational improvement. It must be accompanied with training in how to communicate the style employed to the subordinates. In addition, specific training for subordinates in how to recognize and respond to differing leadership styles is indicated. While a conceptualization of leadership style such as the Tell-SellConsult-Join model employed in this research is intuitively obvious to most people trained in adminis. tration, it is not nearly so obvious to the typical subordinate. It has been our experience in subordinate training programs that presentation of such a simple model is seen by most subordinates as providing meaningful insights never before available. While such training may result in poor supervisors being perceived even more negatively; we believe, in general, training of subordinates is as important, if not more important than training supervisors.

\section{Use of Power}

The results of this study indicate supervisors and subordinates do not agree in their perceptions of what is happening in their relationships. Power is central to effective supervision. However, many supervisory training programs do not focus on the various types of power available to the supervisor and relatively few subordinate training programs include training on how to respond to the use of power by the supervisor or even how to recognize what type of power is being used.

In the data obtained for this study, we found that across the 87 units studied the mean perceptions of amount of power used did not differ between supervisors and subordinates on any dimension. In fact. the absolute means did not differ by as much as two points on any dimension. Yet, in no case were the perceptions positively related and one case (referent power) they were negatively related. This suggests to us that either supervisors or subordinates, or both, are unable to perceive with any accuracy what power is being employed.

Training programs for supervisors need to address the power issue so that the available options for supervisors are expanded. To many supervisors the choice is between coercive and reward power. Yet, our results indicate that both have negative impact on desired outcomes. Similarly, subordinates need to learn to recognize, understand the justification for, and learn appropriate and functional responses to the differential uses of power.

\section{Conflict Management Style}

The management of conflict is a common concern in supervisory training programs, and because of the potential impact of conflict on an organization this emphasis is well placed. The results of this investigation suggest this emphasis should be continued. Supervisors and subordinates could not 
agree on how active the supervisor was in managing conflict. Since many of the behaviors included in the scale (see Note 1) seem quite obvious and observable, this lack of shared perception is disturbing. Only the comparatively gross type of behaviors represented in the dominance scale appear to generate shared perceptions. The reason for this is not clear, but it may relate to the fact that subordinates may tend to feel that the supervisor is more responsible for an active role in managing their conflicts than does the supervisor.

The implication we draw from these results is that training programs in conflict management should be made available for both supervisors and subordinates. Attention must be directed not only toward different methods of managing conflict but also circumstances under which active and passive roles are to be preferred. Such training should lead to more compatible perceptions among supervisors and subordinates and to more positive organizational outcomes.

\section{NOTES}

The items on the Dominance scale were: I become emotionally upset and act as though my feelings are hurt: I use demands to change my subordinates' behavior; I use insults such as yelling and profanity; and I make threats or carry out threats. The items on the Activity scale were: I let the issue resolve itself with no explicit attempts to communicate; dismiss the problem as unimportant; 1 avoid the issue or the problem; | ayoid the issue and communicate with my supervisor about it: l av the subordinate; I communicate indirectly by hinting about the issue: communicate indirectly by joking about the problem; I give in to the subordinate passively; I try to work with the subordinate to reach an agreement on a solution; I disclose information so my subordinate can understand my feelings about the conflict; and I communicate with my subordinate and consider alternative solutions for solving the problem. For subordinates, the personal pronoun "l" was changed to "my supervisor" and other pronouns and verbs changed to be consistent.

The instructions given the subjects were as follows: The purpose of this questionnaire is to measure the kinds of communication behaviors you use when you are in a conflict situation with your subordinate. Please respond us (4) ue (4) usually, (3) sometimes, (2) rarely. (1) never. All of the dominance The first eight activity items, listed above, were scored so that "never" represented a high score; the remaining three items were scored so that "always" represented a high score. The scoring decisions were based on the sign of the factor loadings obtained.

\section{REFERENCES}

Bereison. B. and Steiner, G. A. Human Behavior: An Inventory of Scientific Findings. New York: Harcourt, Brace and World, 1964

Brown, R. Social Psychology. New York: Free Press, 1965.

Cohen, J. Statistical Power Analysis for the Behavioral Sciences. New York: Academic Press, 1977

Deutsch. M. The Resolution of Confict. New Haven and London: Yale University Press. 1973.

Fiedler, F. Engineering the job to fit the manager. Harvard Business Review, $1965,43,115-122$.

French, J. and Raven, B. The bases of social power. In D. Cartwright (Ed.), Studies in Social Power, Ann Arbor, MI: Institute for Social Research, 1959.

Katz, D. and Kahn, R. The Social Psychology of Organizations. New York: John Wiley and Sons, Inc., 1966.

Likert, R. New Patterns of Management. New York: McGraw-Hill Book Co., 1961.

McCroskey, J. C. Oral communication apprehension: A summary of recent research and theory. Human Communication Resesrch, 1977. recent rese日.

McGregor. D. The Human Side of Enterprise. New York: McGraw-Hill Book Co., 1960.

Pelz, D. C. Influence: A key to effective leadership in the first-line supervisor. Personnel, 1952, 29, 209-217.

Richmond, V.P. The relationship between trait and state communication apprehension and interpersonal perceptions during acquaintance stages. Human Communication Research, 1978, 4, 338-349.

Richmond, V. and McCroskey, J. Management communication style, tolerance for disagreement and innovativeness as predictors of employee satisfaction: A comparison of single-factor, and multiplefactor approaches. In D. Nimmo (Ed.), Communication Yearbook III. New Brunswick: Transaction Books, 1979.

Richmond, V. P., McCroskey, J. C., Davis, L. M. and Koontz, K. A. Perceived power as a mediator of management communication style and employee satisfaction: A preliminary investigation. Communica. tion Quarterly, 1980, 28, 37-46.

Sillars. A. Attributions and communication in roommate conflicts. In D. Nimmo (Ed.), Communication Yearbook IV. New Brunswick: Transaction Books, 1979, 217-235.

Smith, P. C., Kendall, L. M. and Hulin, C. L. The Measurement of Satisfaction in Work and Retirement. Chicago: Rand McNally, 1969.

Spielberger, C. D. (Ed.), Anxiety and Behavior. New York: Academic Press, 1966.

Student, K. Supervisory influence and work-group pertormance, Journal of Applied Psychology, 1968, 52, 188-194.

Tannenbaum, R. and Schmidt. W. How to choose a leadership pattern. Harvard Business Review, 1958, 36, 95-101.

Thibaut, J. W. and Riecken, H. W. Authoritarianism, status and the communication of aggression. Human Relations, 1955, 8, 95-120.

Wheeless, L. R. Self-disclosure and interpersonal solidarity: Measurement, validation, and relationships. Human Communication Research, $1976,3,47-61$.

Wheeless, L. R. A follow-up study of the relationships among trust, disclosure, and interpersonal solidarity. Human Communication Research, 1978, 4, 143-157.

Ernest R. May and Dorothy G. Blaney. Careers for Humanists. New York: Academic Press, 1981

This is a curiosity, a little bit of argument, a depressing dose for speech communication scholars. It is all about the decline of the humanities, a pessimistic view of employment prospects for the humanistically educated, a prediction of gloom and doom, aimost apocalyptic in its presentation of dismal prospects.

The only thing about it is that it never mentions speech scholars. Thousands of Ph.D.'s and not a single mention. Maybe it's because speech scholars still get jobs. Maybe it's because they don't accept speech scholars as scholars. Thus Harvard and the State of New York Department of Education do in a whole protession.

Frank L. Mott (Ed.). The Employment Revolution: Young American Women of the 1970s. Cambridge: MIT Press, 1982.

This is a simple book, easy to read if you skip the tables, footnotes, and bibliography that come at you in overwheiming numbers. It all adds up to the premise that women are doing a little better at employment these days than their mothers did, but have a long way to go to catch up to men. If you want details for arguing purposes, take a look at the book. That's what it's about. 